\title{
Psychosocial Factors Associated With Reverse Smoking \\ - A Qualitative Research
}

\author{
Dr. Umesh $\mathrm{K}^{1}$, Dr. Sangeeta ${ }^{1}$, Dr. Pranay Kumar ${ }^{2}$, Dr. Harini ${ }^{3}$, Dr. Pallavi.N ${ }^{4}$
}

\section{ABSTRACT}

Reverse smoking refers to a smoker putting a lit end of the cigarette into his mouth and inhaling the smoke from lit end. Reverse smoking is popular in some parts of India, Srilanka, Venezuela, Panama and Sardinia. Reverse smoking is a risk factor for cancer of the hard palate. Prevention is better than cure, thus its very crucial to identify the factors associated with initiating and abiding by this habit, so that we can try to prevent people from taking up this habit. The current study is conducted with an aim to assess the psychological and social factors associated with reverse smoking. Materials \& methods: the current study is an qualitative research conducted to know the psychological and social factors related to reverse smoking. The information is collected by means of structured interview. The study includes reverse smokers form srikakulam district the sample size is determined by data saturation. Individuals who are psychologically disoriented and who do not give informed consent are excluded. Results: majority of individuals in the current study has started reverse smoking due to the influence of others and majority of them belong to lower SES and are illiterates which suggest that individuals behavior is largely determined by the condition in which they live. Nearly $55 \%$ of the reverse smokers were influenced by their family and friends. Conclusions: complex array of factors influence and determine human behavior major emphasis on health promotion is therefore to make the healthy choices, and highlight that an agenda to improve health outcomes among the poor in India must include effective interventions to control tobacco use.

Keywords: Psychology, reverse smoking, tobacco

Cigarette smoking is the leading cause of preventable death in the world; 100 million people were estimated to have died from causes related to smoking in the 20th century. This is around three times more people than those who died in World War I. The 100 million people who died from smoking in the 20th century died from a preventable cause of death. This trend is continuing into the 21st century, with the World Health Organization estimating that about 5

\footnotetext{
${ }^{1}$ Reader, Department of Public Health Dentistry, Vishnu Dental College and Hospital, Bhimavaram, (A.P).

${ }^{2}$ Tutor, Department of Public Health Dentistry, Vishnu Dental College and Hospital, Bhimavaram, (A.P).

${ }^{3}$ House surgeon, Department of Public Health Dentistry, Vishnu Dental College and Hospital, Bhimavaram, (A.P).

${ }^{4}$ Post graduate student, Dept. of Oral Pathology, Vishnu Dental College, Bhimavaram, (A.P)

(C) 2015 I Umesh, Sangeeta, Kumar, Harini, Pallavi; licensee IJIP. This is an Open Access Research distributed under the terms of the Creative Commons Attribution License (http://creativecommons.org/licenses/by/2.0), which permits unrestricted use, distribution, and reproduction in any Medium, provided the original work is properly cited.
} 


\section{Psychosocial Factors Associated With Reverse Smoking - A Qualitative Research}

million people around the world die from smoking every year. ${ }^{1}$ Researchers have reported that smoking prevalence in 'adults believe that they can easily quit smoking, ignoring its addictive properties, and ultimately believe they can be spared from the long-term effects of smoking. Petraitis and colleagues (1995) suggested that factors affecting tobacco use can be classified along two dimensions-type of influence and level of influence. These authors suggested that three distinct types of influence underlie existing theories of tobacco use social, cultural, and personal. Social influences include the characteristics, beliefs, attitudes, and behaviors of the persons who make up the more intimate support system of adolescents, such as family and friends. Cultural influences include the practices and norms of the broader social environment of adolescents, such as the community, neighborhood, and school. Personal influences include individual biological characteristics, personality traits, affective states, and behavioral skills. ${ }^{2}$

India, tobacco consumption is responsible for half of all the cancers in men and a quarter of all cancers in women. Reverse smoking refers to a smoker putting the lit end of a cigarette into his mouth. The smoker then inhales the smoke from the lit end. In India, it's predominantly prevalent only in the north coastal districts of Andhra Pradesh, especially among the rural, tribal, agricultural and fisher-folk communities of Srikakulam, Vizag, Vizianagaram and West Godavari. There has been no drop in the unique form of cancer called 'chutta' or palate cancer, which occurs due to smoking with the 'reverse' lighted end of the cigarette inside the mouth. India also has one of the highest rates ( $47 \%$ men and $14 \%$ of women-either smoked or chewed tobacco) of oral cancer in the world. The World Health Organization predicts that tobacco deaths in India may exceed 1.5 million annually by $2020 .^{3}$

\section{METHODOLOGY}

The present study is a descriptive qualitative study conducted among the fishermen's of coastal area of Andhra Pradesh, India to understand the psychosocial determinants of reverse smoking. In-depth interviews were conducted with 360 individuals who practiced reverse smoking. The study was carried out for 3 months.

\section{Inclusion criteria}

- Individuals with the habit of reverse smoking residing in coastal areas of Andra Pradesh (Srikakulam, Vizianagaram districts).

\section{Exclusion criteria}

- Individuals who are psychologically disoriented

- Individuals who do not provide consent.

Study sample was selected by employing SNOW BALL SAMPLING TECHNIQUE. The sample size was determined by "DATA SATURATION METHOD” A structured interview method was 


\section{Psychosocial Factors Associated With Reverse Smoking - A Qualitative Research}

employed to collect the data, after obtaining the informed consent from the participants. The structured interview was conducted in local language by a single person fluent in the local language. It consisted of questions related to their demographic profile and reasons for reverse smoking, peer influence and their knowledge related to its effect on health and why they smoke(benefits). The data collected was immediately transcribed. The transcription were read and re-read carefully and different categories were identified. Saturation of categories was attempted using a constant comparative approach, based on it the sample size fixed was 360 . Qualitative thematic content analysis was conducted to develop a preliminary coding scheme.

\section{RESULTS}

Table no. 1 depicts the descriptive statistics of the study participants. The study subjects were largely within the age group of 40 to 70 years(96.7\%) and 3.3\% were above 70 years of age. All the participants were illiterates. Majority of them belonged to low socioeconomic class and all used chutta for smoking.

Analysis of the interview transcripts revealed 5 main reasons to start smoking (table.2). Majority (45\%) had their first puff when their parents asked them to light the chutta for them. Others started smoking by seeing their neighbors smoke(23.3\%), to overcome sickness(15\%), To overcome the cold weather(8.3\%)and surprisingly $8.3 \%$ started smoking as they were advised by rural medical practitioners.

Table no 3 shows the participant's response to a question analyzing the family and peer influence of an individual to persist reverse smoking habit.

When asked about the effects of reverse smoking on health, to our amaze $81.6 \%$ said that it improves digestion and none of them knew about its harmful effects.

When questioned about the social influence of reverse smoking almost 83.3\% said it creates a bond as during smoking they get along together for some time discussing their routine, problems and worries. Reverse smoking provided a platform for social interaction.

\section{DISCUSSION}

There is very limited literature identifying the social and psychological factors influencing the initiation of reverse smoking. The earlier literature has advanced several explanations for reverse smoking, the most prominent being that the chutta is less likely to be extinguished by water being splashed on it during household work, as well as the possibility of hot ashes falling on nursing infants.

1. In contrast to the earlier studies the main reason identified in the current study was peer or parent influence and was associated with any beneficial outcomes like improving digestion and social interaction. $80 \%$ of individuals in the current study had started Reverse Smoking due to the influence of others and majority of them belong to lower SES and are illiterates which suggest 


\section{Psychosocial Factors Associated With Reverse Smoking - A Qualitative Research}

that individuals behavior is largely determined by the condition in which they live (Madarasova Geckova. A $2005^{4}$, Daniel J. Corsi $2013^{5}$ ). Focusing solely on changing lifestyle can be considered a "Victim blaming" approach which is not only ineffective but may also widen health inequalities . The reverse smokers were influenced mainly by their family and friends which is in line with the results of the study conducted by ( Suzanne L Tyas, Linda L Pederson,1998) ${ }^{6}$ on smokers. The lack of lliteracy is one of the major finding suggesting that the people needs to be educated so that they are in a better position to understand the impact of health detrimental habits. Apart from this few people said that they were advised by the rural medical practitioners to smoke. This suggests the need to educate them in addition provide scientifically sound medical care to the people staying at remote areas.

\section{CONCLUSION}

Complex array of factors influence and determine human behaviour. Major emphasis in health promotion is therefore to make the healthy choices. With the extensive knowledge we possess regarding the detrimental health effects associated with this habit, it is time to quit. . Elucidating determinants of cigarette smoking behaviors would aid healthcare professionals to target intervention programs to those most in need.

\section{REFERENCES}

Worldwide smoking statistics [online]. Sans Souci, NSW: Think Quit; 2008 [cited 28 July 2010]. [1]

Petraitis J, Flay BR, Miller TQ Reviewing theories of adolescent substance use: organizing pieces in the puzzle.Psychological Bulletin . 1995;117(1):67-86[2]

Tobacco use in India: prevalence and predictors of smoking and chewing in a national cross sectional household survey. M Rani, S Bonu, P Jha, S N Nguyen, L Jamjoum Tobacco Control 2003[3]

Madarasová Geckova. Aet.al;Influence of socio-economic status, parents and peers on smoking behaviour of adolescents; Eur Addict Res. 2005;11(4):204-9.[4]

Daniel J. Corsi et.al:Socioeconomic and Geographic Patterning of Smoking Behaviour in Canada: A Cross-Sectional Multilevel Analysis: PLoS one journal ; February 28, 2013:pg11-16[5]

Suzanne L Tyas, Linda L Pederson; Psychosocial factors related to adolescent smoking: a critical review of the literature; Tob Control 1998;7:409-420[6] 
Psychosocial Factors Associated With Reverse Smoking - A Qualitative Research

Table 1: Descriptive statistics of the study population

\begin{tabular}{|c|c|}
\hline Variable & Statistical data \\
\hline No of participants & 360 \\
\hline Age range & $\begin{array}{l}40 \text { to } 50 \mathrm{yrs}-38.3 \% \\
50 \text { to } 60 \mathrm{yrs}-31.6 \% \\
61 \text { to } 70 \mathrm{yrs} \_25 \% \\
71 \text { to } 80 \mathrm{yrs}-3.3 \%\end{array}$ \\
\hline $\begin{array}{l}\text { Gender } \\
\qquad \begin{array}{l}\text { Male } \\
\text { female }\end{array}\end{array}$ & $\begin{array}{l}38.7 \% \\
61.3 \%\end{array}$ \\
\hline $\begin{array}{c}\text { Educational level } \\
\text { Illiterates }\end{array}$ & $100 \%$ \\
\hline $\begin{array}{c}\text { Socioeconomic status } \\
\text { Lower lower } \\
\text { Lower middle }\end{array}$ & $\begin{array}{l}98.3 \% \\
1.6 \%\end{array}$ \\
\hline Material used for smoking & chutta \\
\hline
\end{tabular}


Table 2: Reasons for starting reverse smoking

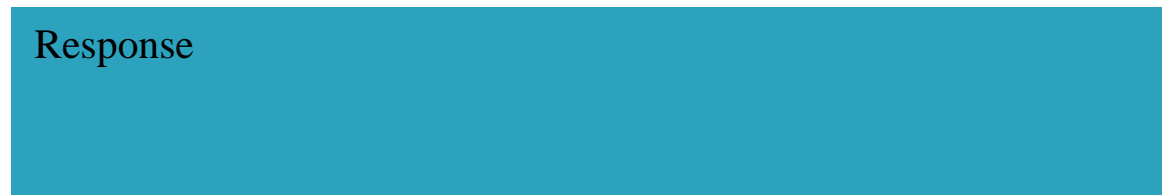

Had their $1^{\text {st }}$ puff when their parents asked them to lit the chutta consecutively got used to it

Learned from their neighbors

To overcome sickness(Edema, toothache, asthma)

To overcome the cold weather

Advised by RMP(rural medical practitioner) doctor for various reasons of sickness like fever, asthma etc..
$23.3 \%$

$15 \%$

\section{Individuals in \%}

$45 \%$

$8.3 \%$

$8.3 \%$

Table 3:Is their anyone in your family and friends who smoke?

\begin{tabular}{|l|l|}
\hline ANSWERS & PERCENTAGE \\
\hline Family & $55 \%$ \\
\hline friends & $21.6 \%$ \\
\hline no & $18.3 \%$ \\
\hline both & $5 \%$ \\
\hline
\end{tabular}

